\title{
REVIEW
}

\section{Immune functions and inflammatory reactions in HLA-B27 positive subjects}

\author{
Risto Tertti, Paavo Toivanen
}

The association between the major histocompatibility antigen HLA-B27 and ankylosing spondylitis is the strongest of all known associations between class I HLA and disease. Over $90 \%$ of patients with ankylosing spondylitis have $B 27,{ }^{1}$ whereas it is found only in $7-15 \%$ of normal white subjects. In addition, B27 is associated with certain reactive inflammatory conditions following gastrointestinal or urogenital infections. For example, about $80 \%$ of patients with reactive arthritis triggered by Yersinia enterocolitica or Yersinia pseudotuberculosis are B27 positive. ${ }^{2}$ Complete Reiter's syndrome, sacroiliitis, and acute anterior uveitis also belong to the same group of diseases. ${ }^{4}$ The collective term spondyloarthropathy is used for these diseases. It is commonly supposed that similar pathogenic mechanisms contribute to the development of all B27 associated diseases. An excess of B27 has also been described in psoriatic arthritis, ${ }^{5}$ in disorders of cardiac conduction, ${ }^{6}$ the latter reflecting the role of ankylosing spondylitis, in schizophrenia, ${ }^{7}$ and even in classical rheumatoid arthritis. ${ }^{8}$

Theories of pathogenetic mechanisms in B27 associated diseases

Studies on ankylosing spondylitis have led to hypotheses of cross tolerance or molecular mimicry. ${ }^{9}$ (For recent reviews see refs 10-12.) Originally, increased faecal carriage of Klebsiella pneumoniae shown in patients with ankylosing spondylitis raised suspicions of a causal link between this bacterium and the disease. ${ }^{13}$ Since then, data have been obtained suggesting that the association between spondyloarthropathies and certain micro-organisms may be due to the molecular similarities of B27 antigen and the infectious agent. Antigenic cross reactivity with the B27 antigen has been reported for yersinia, shigella, and klebsiella. ${ }^{14-16}$ At the genetic level, examples of molecular mimicry include a Klebsiella pneumoniae nitrogenase, a plasmid encoded outer membrane protein YadA of Yersinia enterocolitica and Yersinia pseudotuberculosis, a cationic outer membrane protein OmpH of Salmonella typhimurium, and a 2 megadalton plasmid of arthritogenic Shigella flexneri strains, all with four to six amino acid homology with the HLA-B27 molecule. ${ }^{17-19}$ Only the hexapeptide QTDRED of klebsiella nitrogenase is specifically shared by HLA-B27 (subtypes B27*05, B27*03, and B27HS), however; all other homologies encompass several other HLA molecules not associated with the development of rheumatic diseases. Antibodies against klebsiella, yersinia, and shigella cross reacting with self antigens have been detected in ankylosing spondylitis and reactive arthritis. ${ }^{118}$ There is little evidence to indicate any pathogenic significance of this cross reactivity between the B27 molecule and the microbes, however (Lahesmaa $R$ et al, unpublished data). ${ }^{11} 2021$ In fact, despite demonstration of HLA-B27 cross reacting antibodies in some studies, such antibodies do not correlate with the development of reactive arthritis. ${ }^{22} 23$ B27 positive patients with ankylosing spondylitis show a normal lymphocyte transformation response to autogenous and heterogenous fecal klebsiella strains, which also argues against the significance of antigenic cross reactivity between klebsiella and HLA-B27. ${ }^{24}$

According to a controversial but theoretically satisfactory hypothesis the HLA-B27 molecule might act as a receptor for bacterial products. ${ }^{25}$ Factors released from some klebsiella strains might bind to lymphocytes of B27 positive subjects, making them susceptible to lysis by klebsiella specific antisera. The problem with this theory is that the results have not been reproducible outside the original laboratory.

In addition to these theories, mainly concentrating on the structure of the B27 molecule, it has been suggested that the development of spondyloarthropathies is due to abnormal host defence mechanisms. This might be accomplished by B27 itself or by products of genes closely linked to the HLA-B locus. At present, genes for tumour necrosis factors, for a $70 \mathrm{kD}$ heat shock protein, and for susceptibility to lysis by alloreactive natural killer cells are known as such genes. ${ }^{26-28}$

In this article studies on the immune and inflammatory functions in HLA-B27 positive subjects are reviewed in the light of previously published work. We have tried to rule out the effects of the continuing disease process and the treatments given as far as possible.

\section{Humoral immunity and B27}

There is some evidence for an exceptionally strong antibody response, especially of the $\operatorname{IgA}$ class, in association with the B27 antigen. B27 positive healthy subjects have a higher proportion of the IgAl subclass of their serum IgA than B27 negative controls, and their unstimulated lymphocytes showed decreased IgM production. ${ }^{29}$ Kijlstra et al showed increased serum IgA concentrations in B27 positive patients with anterior uveitis or ankylosing spondylitis compared with B27 negative patients and healthy controls. ${ }^{30}$ Christiansen et al, however, found no difference in serum immunoglobulin concentrations in association with the B27 antigen,
Correspondence to: Dr Tertti.

Accepted for publication 1 March 1991 
though in their study patients with ankylosing spondylitis had increased IgG and IgA concentrations. ${ }^{31}$

Higher antibody titres to streptokinase/ streptodornase have been shown in B27 positive subjects with ankylosing spondylitis and in B27 positive healthy controls than in B27 negative controls. ${ }^{31}$ The number and percentage of $B$ lymphocytes are similar in B27 positive and negative subjects, and no difference has been observed in anti-candida, anti- $E$ coli, antistreptolysin titres, or in titres of antinuclear, parietal cell, and smooth muscle autoantibodies. ${ }^{31}$

It is well documented that patients with yersinia triggered reactive arthritis have a stronger and more persisting IgA class antibody response to the causative micro-organism than patients with uncomplicated yersiniosis. 3233 Additionally, in patients with reactive arthritis those who are B27 positive have a stronger IgA class anti-yersinia antibody response than those who are B27 negative. ${ }^{32}$ B27 positivity does not correlate with IgG and IgM class anti-yersinia antibody response or with in vitro synthesis of IgM, IgA, or IgG class immunoglobulins. ${ }^{34}$ Likewise, in patients with anterior uveitis or ankylosing spondylitis B27 does not correlate with anti-klebsiella titres or with serum IgG concentrations. ${ }^{30}$

Primary and secondary serum antibody responses are similar in B27 positive and negative subjects and do not differ after immunisation with bacteriophage $\phi \times 174^{35}$ or with tetanus toxoid. ${ }^{36}$

\section{Cell mediated immunity and B27}

There is some evidence for weaker cell mediated immune function in association with the B27 antigen. Diminished mixed lymphocyte reaction has been shown in B27 positive healthy controls and relatives of patients with ankylosing spondylitis. ${ }^{37}$ In the same study the mixed lymphocyte reaction was also found to be diminished in patients with ankylosing spondylitis, independently of the B27 antigen. Data suggesting diminished lymphocyte reactivity in association with the B27 antigen have also been reported by other workers as B27 positive healthy subjects and relatives of patients with ankylosing spondylitis have shown lower lymphocyte transformation response to phytohaemagglutinin than B27 negative subjects. ${ }^{31}$ Contradictory findings have also been reported, however. ${ }^{38}{ }^{39}$ Thus although Rola-Pleszczynski et al noted diminished lymphocyte transformation response to phytohaemagglutinin in the presence of autologous serum and diminished lectin induced cytotoxicity of lymphocytes in B27 healthy subjects, in the presence of normal AB serum phytohaemagglutinin responses were higher in B27 positive patients with juvenile rheumatoid arthritis. ${ }^{40}$ Furthermore, B27 positive subjects have been shown to have normal lymphocyte transformation response to candida and streptokinase/streptodornase, as well as normal skin test responses to candida, purified protein derivative, or streptokinase/streptodornase $^{31}$; neither is there any difference in the percentage or number of $T$ lymphocytes. ${ }^{31} 38$
Studying Reiter's syndrome, Bengtsson et al found increased lymphocyte transformation response to yersinia antigen in patients who were B27 positive. ${ }^{41}$ Most of their patients had Chlamydia trachomatis as the triggering agent, and no difference was noted in the response to chlamydia.

After immunisation with tetanus toxoid subjects who are B27 positive respond more strongly to tetanus toxoid in an in vitro lymphocyte transformation test than those who are B27 negative, but normally to purified protein derivative, phytohaemagglutinin streptokinase/ streptodornase, candida, and mumps antigens. ${ }^{36}$ In addition, B27 positive and negative subjects immunised with tetanus toxoid did not differ in their induction of suppressor factors or leucocyte migration inhibitory factor.

\section{Inflammatory reaction and B27}

Animal models of adjuvant arthritis and endotoxin induced uveitis have led to the proposal that the spondyloarthropathies are due to a B27 associated enhanced sensitivity to inflammatory mediators. ${ }^{42}$ There are some human data to indicate increased activity of polymorphonuclear leucocyte function associated with B27. Increased polymorphonuclear leucocyte chemotaxis and chemokinesis attributable to the B27 antigen has been shown in patients with previous yersinia triggered reactive arthritis; no difference was found in the spontaneous motility of the polymorphonuclear leucocytes. ${ }^{43}$ In other studies, however, serum from B27 positive subjects has shown a greater ability to stimulate random migration of polymorphonuclear leucocytes. ${ }^{44}$ No difference was noted in the chemotactic ability of B27 serum samples. Pease et al detected increased neutrophil chemotaxis associated with the B27 antigen but normal random migration of polymorphonuclear leucocytes. ${ }^{45}$ Monocyte migration, on the contrary, seems to be normal. ${ }^{36}$

Abnormal respiratory burst activity of polymorphonuclear leucocytes from B27 positive subjects has not been reported. Repo et al, ${ }^{46}$ Miller and Russell, ${ }^{47}$ and Tertti ${ }^{48}$ detected no difference in superoxide production or chemiluminescence response between polymorphonuclear leucocytes from B27 positive and negative subjects when stimulated by $N$-formylmethionyl-leucyl-phenylalanine or opsonised zymosan. It is also obvious that neutrophil adherence and phagocytosis are normal in B27 positive subjects. ${ }^{45} 46$ Repo et al demonstrated a normal ability for in vitro killing of the virulent Yersinia enterocolitica micro-organism. ${ }^{46}$

The inflammatory parameters in B27 positive and negative subjects have also been compared in in vivo assays. The chemotactic function of polymorphonuclear leucocytes from $B 27$ positive subjects seems to be enhanced in vivo. ${ }^{49}$ B27 positive subjects also have a tendency towards increased production of vasodilatory prostaglandins in vivo. ${ }^{49}$

In addition to enhanced polymorphonuclear leucocyte activity, humoral inflammatory mechanisms may also be exaggerated in B27 positive subjects. Increased production of 
tumour necrosis factors and interleukin-1 has been reported. ${ }^{50}$ Furthermore, increased production of the anaphylatoxin C3a and C3d,g in vitro as stimulated by lipopolysaccharide has been noted in B27 positive subjects, while the concentrations of complement factors are normal. ${ }^{51}$ Interestingly, low concentrations of complement $\mathrm{C} 3 \mathrm{~b}$ receptors (CR1) on erythrocytes have been associated with HLA-B27 in normal subjects ${ }^{52}$ and in yersinia triggered reactive arthritis. ${ }^{53}$ Similarly, lack of $\mathrm{C} 3 \mathrm{~b}$ receptors on erythrocytes has been associated with B27 positivity in patients with juvenile rheumatoid arthritis. ${ }^{54}$ It is possible that this kind of deficiency might cause ineffective elimination of foreign antigens and, if accompanied by exaggerated inflammatory mechanisms, further contribute to the pathogenesis of B27 associated diseases.

In their recent studies Repo et al re-evaluated some of their findings indicating increased polymorphonuclear leucocyte functions in association with B27 antigen. They noted that serum samples of B27 positive children have normal ability to enhance neutrophil migration. ${ }^{55}$ They concluded that the difference between B27 positive and negative subjects may be acquired secondarily and is not genetically determined. In further studies Pease et al also suggest, in contrast with their previous work, ${ }^{45}$ that healthy B27 positive subjects and B27 positive relatives of patients with ankylosing spondylitis have normal neutrophil motility and that the previously noted differences might be due to the disease itself or to the drugs used. ${ }^{56}$

\section{Concluding remarks}

Obviously no definite differences in the immune and inflammatory functions of B27 positive and negative subjects are apparent as each observation is matched by a contradictory report. Nevertheless, it is tempting to mention some tendencies noted to be associated with B27: (a) antibody levels to some antigens may be increased, especially in the IgA class; $(b)$ cell mediated immunity may be diminished in some in vitro systems; $(c)$ some functions of cellular and humoral inflammatory reaction may be increased, and elimination of circulating antigens by certain immune functions may be impaired.

None of the tendencies is prominent enough to explain the disease associations of B27, but one functional aspect has so far been almost completely neglected-the cellular processing and presentation of antigens.

Class I HLA molecules present on the cell surface 'endogenous' antigens - that is, antigens synthesised within the antigen presenting $\mathrm{cell}^{57}$; the cells responding to the antigen presentation are usually cytostatic CD8 positive $T$ cells. If this pathway could be shown to be aberrant in B27 positive subjects it would be a key to understanding the pathogenesis of B27 associated diseases. So far, no available evidence points in this interesting direction.

For the structural features of the B27 molecule to be decisive they should be those in the common determinants of the molecule because all three major subtypes of B27 are equally associated with disease. ${ }^{58}$ Consistent with this is the finding that all examples of molecular mimicry known between bacteria and B27 reside in amino acids 70-78 in the $\alpha$ helix of the $\alpha_{1}$ domain of the B27 molecule (the site binding antigenic peptide), ${ }^{1120}$ and seven of these nine amino acids are shared by all subtypes of B27.

There is little to show anything in common between the bacterial structures potentially crucial for the pathogenesis of B27 associated diseases. One clue might be the presence of an analogously constructed lipopolysaccharide in the bacterial species triggering reactive arthritis, its presence in the inflamed joint, and the longlasting antibody response against it. ${ }^{59-63}$ Another possible light in the darkness of B27 disease may be the recent demonstration of spontaneous spondyloarthropathy in B27 transgenic rats. ${ }^{64}$

Our original studies were supported by a grant from Sigrid Juélius Foundation.

1 Brewerton D A, Caffrey M, Hart F D, James D C O, Nicholls A, Sturrock R D. Ankylosing spondylitis and HLA-A 27. Lancet 1973; i: 904-7.

2 Aho $K$, Ahvonen $P$, Lassus A, Sievers $K$, Tiilikainen A. HLA-A antigen 27 and reactive arthritis. Lancet 1973; ii: 157.

3 Leirisalo-Repo M, Skylv G, Kousa M, et al. Follow up study on patients with Reiter's disease and reactive arthritis, with special reference to HLA-B27. Arthritis Rheum 1982; 25: $249-59$.

4 Linssen A, Feltkamp T E W. B27 positive diseases versus B27 negative diseases. Ann Rheum Dis 1988; 47: 431-9.

5 Armstrong R D, Panayi G S, Welsh K I. Histocompatibility antigens in psoriasis, psoriatic arthropathy and ankylosing spondylitis. Ann Rheron Dis 1983; 42: 142-6.

6 Bergfelt L, Möller E. Complete heart block-another HLAB27 associated disease manifestation. Tissue Antigens 1983; 21: 385-90.

7 Rösler M, Bellaire W, Gressnich N, Giannitsis D, Jarovici A. HLA antigens in schizophrenia, major depressive disorder, HLA antigens in schizophrenia, major depressive disorder, 1983; 172: 57-65.

8 Isomäki H, Nissilä M, Koota K, Martio J. HL-A27 and rheumatoid arthritis. Lancet 1974; ii: 1212-3.

9 Ebringer A, Baines M, Ptaszynska T. Spondyloarthritis, uveitis, HLA-B27 and klebsiella. Immunol Rev 1985; 86: 101-16.

10 Benjamin R, Parham P. Guilt by association: HLA-B27 and ankylosing spondylitis. Immunol Today 1990; 11: 137-42.

11 Lahesmaa R, Skurnik M, Toivanen P. Molecular mimicry: any role in the pathogenesis of spondyloarthropathies? Contrib Microbiol Immunol (in press).

12 Gaston J S H. How does HLA-B27 confer susceptibility to inflammatory arthritis? Clin Exp Immunol 1990; 82: 1-2.

13 Ebringer R W, Cooke D, Cadwell D, Cowling A, Ebringer A. Ankylosing spondylitis: klebsiella and HLA-B27. Ankylosing spondylitis: kebsiel

14 van Bohemen C G, Grumete F C, Zanen H C. Identification of HLA-B27M1 and-M2 cross-reactive antigens in klebsiella, shigella, and yersinia. Immunology 1984; 52: 607-10.

15 Williams K M, Raybourne R B. Demonstration of crossreactivity between bacterial antigens and class I human leukocyte antigens by using monoclonal antibodies to Shigella flexneri. Infect Immun 1990; 58: 1774-81.

16 Chen J-H, Kono D H, Yong Z, Park M S, Oldstone M M B A, Yu D T Y. A Yersinia pseudotuberculosis protein which cross-reacts with HLA-B27. I Immunol 1987; 139: 3003-11.

17 Lahesmaa R, Skurnik M, Vaara M, et al. Molecular mimicr between HLA-B27 and yersinia, salmonella, shigella and klebsiella within the same region of HLA $\alpha$ 1-helix. Clin Exp Immunol (in press).

18 Schwimmbeck (in press). Autoantibodies to HLA B27 in the sera of HLA B27 Autoantibodies to HLA B27 in the sera of HLA B27
patients with ankylosing spondylitis and Reiter's syndrome. Molecular mimicry with Klebsiella pneumoniae as a potential mechanism of autoimmune disease. $\mathcal{F}$ Exp Med 1987, 166: $173-81$.

19 Stieglitz H, Fosmire S, Lipsky P. Identification of a 2-Md plasmid from Shigella flexneri associated with reactive arthritis. Arthritis Rhewn 1989; 32: 937-46.

20 Ivanyi P. Dysfunction of HLA-B27. Scand $\mathcal{Y}$ Rheumatol 1990 (suppl 987): 51-69.

21 de Vries D D, Dekker-Sayes A J, Gyodi E, Ivanyi P. Failure to detect cross-reacting antibodies to HLA-B27.5 and Klebsiella pneumoniae in sera from patients with ankylosing spondylitis and Reiter's syndrome. Scand $\mathcal{f} R$ heumato 1990; (suppl 87): 72-3.

22 Cavender $D$, Ziff $M$. Anti-HLA-B27 antibodies in sera from patients with gram-negative bacterial infections. Arthritis patients with gram-negat
Rheum 1986; 29: 352-7. 
23 van Bohemen C G, Nabbe A J J M, Dinant H J, Grumet F C, Landheer J E, Zanen H C. Lack of serologically defined arthritogenic Shigella flexneri cell envelope antigens in post-dysenteric arthritis. Immunol Lett 1986; 13: 197-201.

24 Kinsella T D, Lanteigne C, Fritzler M J, Lewkonia R M. Absence of impaired lymphocyte transformation to KlebAbsence of impaired lymphocyte transformation to Kleb-
siella spp. in ankylosing spondylitis. Ann Rherm Dis 1984; 43: $590-3$.

25 Geczy A F, Alexander K, Bashir H V, Edmonds J. A factor(s) in klebsiella culture filtrates specifically modifies an HLAB27-associated cell-surface component. Nature 1980; 283: $782-4$

26 Spies T, Blanck G, Bresnahan M, Sands J, Strominger J L. A new cluster of genes within the human major histocompatibility complex. Science 1989; 243: 214-7.

27 Sargent C A, Dunham I, Trowsdale J, Campbell R D. Human histocompatibility complex contains genes for the major heat shock protein HSP70. Proc Natl Acad Sci USA 1989; 86: 1968-72.

28 Ciccone E, Colonna M, Viale O, et al. Susceptibility or resistance to lysis by alloreactive natural killer cells is governed by a gene in the human major histocompatibility complex between BF and HLA-B. Proc Natl Sci USA complex between

29 van den Wall Bake A W L, Peeters A J, van der Ark A, Daha $M R$, Cats A, van Es $\mathrm{L} A$. Immunoglobulin synthesis by peripheral blood lymphocytes in patients with ankylosing spondylitis. F R heumatol 1988; 15: 1410-4.

30 Kijlstra A, Luyendijk L, van der Gaag R, van Kregten E, Linssen A, Willers J M N.. IgG and IgA immune response against klebsiella in HLA-B27 associated anterior uveitis. Br F Ophthalmol 1986; 70: 85-8.

31 Christiansen F T, Hawkins B R, Dawkins R L. Immune function in ankylosing spondylitics and their relatives: influence of disease and HLA B27. Clin Exp Immunol 1978; 33: $270-5$.

32 Granfors $\mathrm{K}$, Viljanen $M$, Tiilikainen A, Toivanen A. Persistence of IgM, IgG and IgA class yersinia antibodies in tence of IgM, IgG and IgA class yersinia antibo
yersinia arthritis. $\mathcal{I}$ Infect Dis 1980; 141: 424-9.

33 Toivanen A, Lahesmaa-Rantala R, Vuento R, Granfors $K$. Association of persisting IgA response with yersinia triggered reactive arthritis: a study of 104 patients. Ann Rheum Dis 1987; 46: 898-901.

34 Vuento R, Eskola J, Leino R, Koskimies S, Viander M. IgM, IgG, and IgA synthesis in vitro in persons suffering from yersinia arthritis and in patients with ankylosing spondylitis. Ann Rheum Dis 1984; 43: 186-91.

35 Bucknall R, Leirisalo-Repo M, Laitinen O, Jones J V. Antibody producing capacity to the bacteriophage $\phi X 174$ in yersinia arthritis. Ann Rheum Dis 1987; 46: 883-8.

36 Repo H, Leirisalo-Repo MM, Gripenberg M, Koskimies S, Kontiainen S, Laitinen O. Yersinia arthritis, immune functions and histocompatibility antigens. Acta Pathol Microbiol Immunol Scand [C] 1986; 94: 245-52.

37 Nikbin B, Brewerton D A, James D C O, Hobbs J R. Diminished mixed lymphocyte reaction in ankylosing Diminished mixed lymphocyte reaction in ankylosing
spondylitis, relatives, and normal individuals all with spondylitis, relatives, and normal individu
HLA-B27. Ann Rheum Dis 1976; 35: 37-9.

38 Fan P T, Clements P J, Yu D T Y, Opelz G, Bluestone R. Lymphocyte abnormalities in ankylosing spondylitis. Ann Rhew Dis 1977; 36: 471-3.

39 Repo H, Leirisalo-Repo M. Immune function in patients with previous yersinia arthritis: lymphocyte responses to PHA and Staphylococcus aureus strain Cowan I. Acto Pathol Microbiol Immunol Scand [C] 1986; 94: $39-43$.

40 Rola-Pleszczynski M, Paré C, Camerlain M. HLA-B27 positive juvenile rheumatoid arthritis: altered lymphocyte responses to mitogens and low cytotoxic activity. Clin responses to mitogens and low cytotoxic

41 Bengtsson A, Holmlund G, Kihlström E, Lindblom B. Lymphocyte stimulation in Reiter's syndrome. Scand $\mathcal{J}$ Rhermatol 1985; 14: 381-5.

42 Rosenbaum J T. Why HLA-B27: an analysis based on two animal models. Ann Intern Med 1981; 94: 261-3.

43 Leirisalo M, Repo H, Tiilikainen A, Kosunen T U, Laitinen $O$. Chemotaxis in yersinia arthritis. HLA-B27 positive neutrophils show high stimulated motility in vitro. Arthritis Rheum 1980; 23: 1036-44.
44 Repo H, Leirisalo M, Tiilikainen A, Laitinen O. Chemotaxis in yersinia arthritis. In vitro stimulation of neutrophil migration by HLA-B27 positive and negative sera. Arthritis Rheum 1982; 25: 655-61.

45 Pease C T, Fordham J N, Currey H L F. Polymorphonuclear cell motility, ankylosing spondylitis, and HLA-B27. Ann Rherum Dis 1984; 43: $279-84$.

46 Repo H, Leirisalo-Repo M, Skurnik M, Tiilikainen A Neutrophil function and HLA-B27. Superoxide production and yersinicidal activity of neutrophils from patients with previous yersinia arthritis. Med Biol 1984; 62: 91-4.

47 Miller C, Russell A S. The generation of superoxide anions by polymorphonuclear leucocytes from patients with ankylosing spondylitis in response to the stimulant f-met-leu-phe. Clin Exp Rheumatol 1986; 4: 135-7.

48 Tertti R. Polymorphonuclear leukocyte chemiluminescence response in HLA-B27 positive and negative arthritis response in HLA-B27 positive and
patients. Rheumatol Int 1989; 8: 279-82.

49 Koivuranta-Vaara $P$, Repo $H$, Leirisalo M, Kiistala U, Österman T, Vapaatalo H. Enhanced neutrophil migratio in vivo HLÁ B27 positive subjects. Ann Rheum Dis 1984; 43: 181-5.

50 Repo H, Jäättelä M, Leirisalo-Repo M, Hurme M. Production of tumour necrosis factor and interleukin 1 by monocytes of patients with previous yersinia arthritis. Clin Exp Immunol 1988; 72: 410-4.

51 Meri S, Partanen J, Leirisalo-Repo M, Repo H. Complement activation and HLA-B27. Ann Rherom Dis 1988; 47: 210-4.

52 Thomsen B S, Jacobsen S E H, Nielsen H, Jakobsen B K Sorensen H. Normal distribution of complement C3b receptor (CR1) numbers in blood donors: low levels are associated with HLA-B27. Complement 1986; 3: 79-87.

53 Lahesmaa-Rantala R, Eerola E, Toivanen A. Reduced erythrocyte C3b receptor (CR1) activity in patients with yersinia triggered reactive arthritis. Ann Rheum Dis (in press)

54 Măkelä A-L, Eerola E, Lehtonen O-P, Ruuska P, Lantto R. Erythrocyte $\mathrm{C} 3 \mathrm{~b}$ receptors in juvenile rheumatoid arthritis. N Engl F Med 1983; 309: 673.

55 Repo H, Leirisalo-Repo M, Koskimies S. Effects of HLAB27 positive and negative sera on migration of polymorphonuclear leukocytes in vitro. Clin Exp Rheumatol 1988; 6: 227-31.

56 Pease C T, Fennell M, Brewerton D A. Polymorphonuclear leucocyte motility in men with ankylosing spondylitis. Ann Rheum Dis 1989; 48: 35-41.

57 Bevan M J. Class discrimination in the world of immunology. Nature 1987; 325: 192-4.

58 Breuer-Vriesendorp B S, Dekker-Saeys A J, Ivanyi P. Distribution of HLA-B27 subtypes in patients with ankylosing spondylitis: the disease is associated with a common determinant of the various B27 molecules. Ann Rheum Dis 1987; 46: 353-6.

59 Granfors $K$, Jalkanen $S$, von Essen $R$, et al. Yersinia antigens in synovial-fluid cells from patients with reactive arthritis. N Engl F Med 1989; 320: 216-21.

60 Granfors $\mathrm{K}$, Jalkanen S, Lindberg A A, et al. Salmonella lipopolysaccharide in synovial cells from patients with reactive arthritis. Lancet 1990; 335: 685-8.

61 Viitanen A-M, Arstila T P, Lahesmaa R, Granfors $K$, Skurnik M, Toivanen P. Application of the polymerase chain reaction and immunofluorescence techniques to the detection of bacteria in yersinia-triggered reactive arthritis. Arthritis Rheum 1991; 34: 89-96.

62 Merilahti-Palo R, Söderström K-O, Lahesmaa-Rantala R, Granfors $K$, Toivanen A. Bacterial antigens in synovial biopsy specimens in yersinia triggered reactive arthritis. Ann Rheum Dis 1991; 50: 87-90.

63 Granfors $K$, Vuento $R$, Toivanen A. Host-microbe interaction in reactive arthritis. In: Toivanen $A$ Toivanen $P$, action in reactive arthritis. In: Toivanen A, Toivanen P, $15-49$.

64 Hammer R E, Maika S D, Richardson J A, Tang J-P, Taurog $J$ D. Spontaneous inflammatory disease in transgenic rats expressing HLA-B27 and human $\beta_{2}$ m: an animal model of HLA-B27-associated human disorders. Cell 1990; 63: 1099-112. 